rev.relac.int.estrateg.segur.8(1):137-160,2013

\title{
LA PARTICIPACIÓN CIUDADANA DE LOS JÓVENES MEXICANOS EN LA CONSTRUCCIÓN SOCIAL Y DEMOCRÁTICA DEL PAíS AL INICIO DEL SIGLO XXI*
}

\author{
Jorge E. Horbath** \\ Ma. Amalia Gracia ${ }^{* * *}$
}

\section{RESUMEN}

En este artículo, más que establecer una definición de lo que debería ser la participación ciudadana, lo que nos interesa es indagar cuáles son los determinantes de la participación ciudadana entre los jóvenes mexicanos. Esto nos parece sumamente importante ya que en los jóvenes y en la construcción de la participación ciudadana se encuentran las bases de la conformación de una sociedad en los sistemas democráticos sólidos. Asimismo, el relevo generacional de la población permite educar a las sociedades futuras para consolidar procesos democratizantes. El cambio generacional en el sistema democrático en México está obligando a que se den procesos de mayor incorporación de los jóvenes a la vida democrática del país, fortaleciendo la transparencia en las

* Este documento se elaboró a partir del proyecto "Aproximación al impacto del programa de Formación Cívica y Ética en escuelas secundarias del Distrito Federal: evaluación y recomendaciones", financiado por el Instituto Nacional de Desarrollo Social (INDESOL).

** Investigador titular, Departamento Sociedad, Cultura y Salud, El Colegio de la Frontera Sur (ECOSUR), Unidad Chetumal. Miembro del Sistema Nacional de Investigadores, S.N.I. Nivel 1 del CONACYT. jhorbath@ecosur.edu.mx

*** Investigadora titular, Departamento Sociedad, Cultura y Salud, El Colegio de la Frontera Sur (ECOSUR), Unidad Chetumal. Miembro del Sistema Nacional de Investigadores, S.N.I. Nivel 1 del CONACYT. magracia@ecosur.edu.mx 
instituciones democráticas para incentivar la credibilidad de la población joven que generacionalmente tiene mayor escolaridad y su capacidad de crítica a las propuestas electorales es cada vez mayor.

Palabras Clave: Participación ciudadana, Jóvenes, Ciudadanía.

\title{
CITIZEN PARTICIPATION OF MEXICAN YOUTH IN THE SOCIAL AND DEMOCRATIC CONSTRUCTION OF THE COUNTRY AT THE BEGINNING OF THE XXI CENTURY
}

\begin{abstract}
In this article, rather than a definition of what should be public participation, what we wish is to find out which are the determinants of civic participation among Mexican youth. This seems very important because in the young and in the construction of citizen participation are the foundations of a society in sound democratic systems. Also, the next generation of the population can educate future societies to consolidate democratic processes. Generational change in the democratic system in Mexico is forcing processes that give greater participation of young people in the democratic life of the country, strengthening transparency in democratic institutions to boost the credibility of the young population, which now has higher education and its critical skills to election proposals keeps increasing.
\end{abstract}

Keywords: Citizen participation, Youth, Citizenship.

\section{PARTICIPAÇÃO CIDADÃ DOS JOVENS MEXICANOS NA CONSTRUÇÃO SOCIAL E DEMOCRÁTICA DO PAÍS NO INÍCIO DO SÉCULO XXI}

\section{RESUMO}

Neste artigo, ao invés de estabelecer uma definição do que deveria ser a participação cidadã, queremos saber quais são os determinantes da participação cidadã dos jovens mexicanos. Isso parece muito importante porque nos jovens e na construção da participação cidadã são forjados os alicerces da formação de uma sociedade nos sistemas democráticos sólidos. Além disso, a próxima geração da população pode educar sociedades futuras para consolidar os processos democratizantes. A mudança geracional no sistema democrático no México está forçando os processos que dão uma maior inclusão dos jovens para a vida democrática do país, fortalecendo a transparência nas instituições democráticas para incentivar a credibilidade da população jovem que, em relação ao aspecto geracional, tem uma maior escolaridade e sua capacidade de crítica é cada vez maior.

Palavras-chave: Participação Cidadã, Juventude, Cidadania. 


\section{INTRODUCCIÓN}

En este artículo, más que establecer una definición de lo que debería ser la participación ciudadana, lo que nos interesa es indagar cuáles son los determinantes de la participación ciudadana entre los jóvenes mexicanos. Esto nos parece sumamente importante ya que en los jóvenes y en la construcción de la participación ciudadana se encuentran las bases de la conformación de una sociedad en los sistemas democráticos sólidos. Asimismo, el relevo generacional de la población permite educar a las sociedades futuras para consolidar procesos democratizantes. Siguiendo los postulados teóricos y conceptuales de la ciudadanía y sus formas de expresión, este documento muestra los aspectos de mayor relevancia en las prácticas ciudadanas de los jóvenes mexicanos captados por la Encuesta Nacional sobre Cultura Política y Prácticas Ciudadanas (ENCUP) de 2003, efectuando una descripción de los principales resultados y realizando una propuesta de análisis multivariado haciendo uso de los modelos logísticos para estudiar la relación entre condiciones socioeconómicas y participación ciudadana de los jóvenes mexicanos, descrita esta última como las acciones ciudadanas y la participación electoral.

\section{MARCO TEÓRICO}

Considerando que la acción de la ciudadanía encaminada al ejercicio de la construcción de la sociedad en diferentes esferas, es necesario tener un referente de lo que entendemos como "ciudadanía". La ciudadanía puede definirse como un grupo de prácticas culturales, simbólicas y económicas, así como el conjunto de obligaciones y derechos de carácter legal, político y social que definen a un individuo en relación con el Estado (Isin, 1996: 21). De allí que las acciones que realizan los individuos se encuentran vinculadas por una percepción de identidad colectiva. La identidad es el sentimiento de pertenencia a una colectividad que genera la percepción de estar en igualdad de condiciones, lo cual puede facilitar la organización ciudadana (Bolos, 1995: 106-107), permitiendo a los actores sociales "ordenar preferencias y escoger, en consecuencia, ciertas alternativas de acción" (Giménez, 2000: 71-72).

Por ello, el concepto de ciudadanía se vincula con el Estado nación y también con el de nacionalidad, siendo el escenario local el lugar donde se conforman los componentes identitarios de la ciudadanía, pues en él los ciudadanos logran realizar las prácticas políticas debido a la información factible de su participación efectiva en lo público; por tanto, se logra una aproximación entre la cotidianidad de los ciudadanos y la esfera política, abriéndose como ámbito sacro cerrado y permite el ingreso al accionar ciudadana (Carrión y Wollrad, 1999: 16).

Las identidades también se sustentan en los imaginarios sociales que son los medios para comprender lo social desde lo local y emanan sus configuraciones desde ese ámbito de entidades sociales que intervienen en la actividad cotidiana (Parameshwar, 2002; Calhoun, 2002; Taylor, 2002; Paley, 2002: 471). Dichos imaginarios también son definidos como las formas de elegir su 
identidad por parte de un colectivo o comunidad, construyendo representaciones de sí, exponiendo y adjudicando creencias, asignando roles sociales y jerarquías, encaminados a crear modelos de reproducción social (Baczko, 1991: 28).

Existen varias definiciones de participación ciudadana en diversos ámbitos disciplinarios y políticos; sin embargo, para los fines de este trabajo retomaremos la participación ciudadana como el comportamiento que demuestra el interés e involucramiento de los jóvenes ciudadanos en los asuntos públicos. Sydney Verba define la participación como "aquellas actividades legales de los ciudadanos privados que están más o menos enfocadas a influir en la selección del personal de gobierno y/o en las acciones que éste realice" (1978: 46). Existen diversas formas de participación y en distintos niveles. Sin embargo, su manifestación primordial es el ejercicio del voto para elegir a los representantes populares en el ámbito local y federal.

La más estrecha forma de participación, y generalmente referida al espacio político electoral, ubica la participación en el sufragio, y en la calidad del mismo, es decir la participación queda referida a la concurrencia a las urnas y la emisión de un voto independiente. Lo contrario de participar es abstenerse de votar o hacerlo como producto de un acto de manipulación. En este sentido, particularmente en ocasión de las campañas electorales, encontramos que los resultados que arrojan las encuestas se toman como indicadores de la opinión mayoritaria de la ciudadanía. En este caso, participar es sinónimo de opinar (Portal, 2004: 369).

Los dirigentes de organizaciones populares, las ONG's y teóricos de izquierda, ubican el ejercicio de la ciudadanía en una participación más plena de los habitantes de la ciudad en los problemas que los aquejan disponiendo de una cuota mayor de poder y de recursos para poder organizarse en instancias de negociación ante diversas esferas del poder: "para alcanzar en nuestra ciudad el objetivo más importante del fin del siglo: la democracia, es necesario que los ciudadanos participen, y para esto es necesario que se organicen en sus espacios naturales que son territoriales, con valores culturales y tradiciones afirmadas en el tiempo, con formas de subsistencia material y ocupaciones específicas" (Zermeño, 2004: 158). También la vinculan con la capacidad de movilización y presión de los sectores populares frente a las autoridades, es decir, con el hecho de concurrir a marchas, plantones o realizar huelgas y protestas de todo tipo para exigir o demandar algo concreto.

En los partidos políticos tradicionales, la participación se entiende más en términos clientelistas, y, aunque no lo admitan de manera explícita, por la vía de los hechos, participar implica formar parte de una red de intercambio de bienes y servicios por favores políticos (Horbath, 2002: 185-232). Lo cual se ve favorecido e instrumentado por diversos caciquismos y organizaciones intermedias locales, pues los partidos adoptan una estrategia proselitista para relacionarse con la ciudadanía, dando lugar a una perspectiva clientelar con que visualizan a la ciudadanía (Tejera, 2006: 48).

Por último, encontramos formas "más cotidianas y menos visibles" (Portal, 2004: 374) que promueven la participación desde lo local. Dentro de esta modalidad podemos encuadrar las 
actividades religiosas, comunitarias y sociales en la localidad. En algunos casos están reguladas por ciclos anuales. Por ejemplo, con motivo de las fiestas patronales, las personas se involucran más activamente en el año que les corresponde según un calendario establecido de antemano, pero pueden desentenderse por completo cuando ya se cumplió su obligación. En el mismo sentido, muchas instancias de participación colectiva sólo se activan cuando se acercan las fechas de las fiestas o eventos. Por último, todas estas formas organizativas están atravesadas por redes de parentesco y la celebración de eventos familiares que la mayoría de las veces incluyen a una buena parte de la comunidad. De ahí que la gente no separe en el discurso su participación en actos privados de los públicos, porque de hecho están mezclados en la vida cotidiana. Si un instrumento de indagación que busca explorar las modalidades de participación y medir su eficacia no contempla esta situación en el diseño de sus preguntas, puede provocar un subregistro de algunas formas participativas o una distorsión en la interpretación de los resultados.

De esta manera, ante las diferentes definiciones del concepto de participación ciudadana, retomamos la reflexión de Winocur y Horbath (2002: 483), donde alrededor del término participación ocurren desencuentros en las representaciones y sentidos sobre este concepto, ya que generalmente se piensa que al hablar de participación todos entendemos lo mismo; además, puede ser que al tratar de medir la participación por medio de una encuesta las personas o los jóvenes interpreten las preguntas con los significados que han experimentado como participación y se terminen midiendo las diferentes representaciones.

Otro punto a tener en cuenta es la variabilidad de las encuestas, es decir la comparabilidad posible entre la ENCUP-2001 y la ENCUP-2003.La segunda ENCUP incluye ciertas preguntas que no fueron formuladas en el levantamiento del 2001, explorando nuevos temas y modificando tanto el formato como las opciones de respuesta de algunas preguntas, reduciendo la comparabilidad directa de la información levantada en el 2001 con las del 2003.

\section{Tabla 1. Encuesta Nacional sobre Cultura Política y Prácticas Ciudadanas: Algunas diferencias}

\begin{tabular}{|l|c|c|}
\hline & ENCUP-2001 & ENCUP-2003 \\
\hline Número de preguntas & 121 & 74 \\
Muestra & 5,015 & 5,256 \\
Entrevistas efectivas & 4,183 & 4,580 \\
Miembros del panel & - & 2,789 re-entrevistados \\
Fecha de levantamiento & Noviembre de 2001 & Febrero de 2003 \\
Entrevistas & - & 200 \\
Opciones de respuestas & & \\
\hline
\end{tabular}

Fuente: Cálculos propios a partir de la ENCUP 2003. 


\section{EL PERFIL SOCIO-DEMOGRÁFICO DE LOS JÓVENES MEXICANOS}

A partir de los resultados de la Encuesta Nacional sobre Cultura Política y Prácticas Ciudadanas (ENCUP) del 2003, realizada por la Secretaría de Gobierno a 4580 individuos mayores de 18 años, se seleccionaron 997 jóvenes de 18 a 29 años, identificando dos grupos: uno de Jóvenes, individuos con edades entre 18 y 24 años, y el segundo de Adultos jóvenes, individuos con edades entre 25 y 29 años; a partir de estos se analizaron las prácticas de la participación ciudadana de los jóvenes mexicanos y los determinantes sociodemográficos que pueden estar determinando este tipo de prácticas.

De acuerdo con la muestra de jóvenes encuestados, los jóvenes mexicanos están representados por un $38.9 \%$ de hombres y un $61.1 \%$ de mujeres, distribuidos por edades simples, con una base angosta a los 18 años y un aumento proporcional de jóvenes a medida que aumenta la edad; debido a que esta distribución es algo diferente al promedio nacional, se puede pensar que estas características pueden influir de alguna manera en las prácticas de participación ciudadana, pero principalmente queremos observar si las mujeres y los hombres tienen diferencias en la participación ciudadana o si su edad puede influir en una mayor o menor participación.

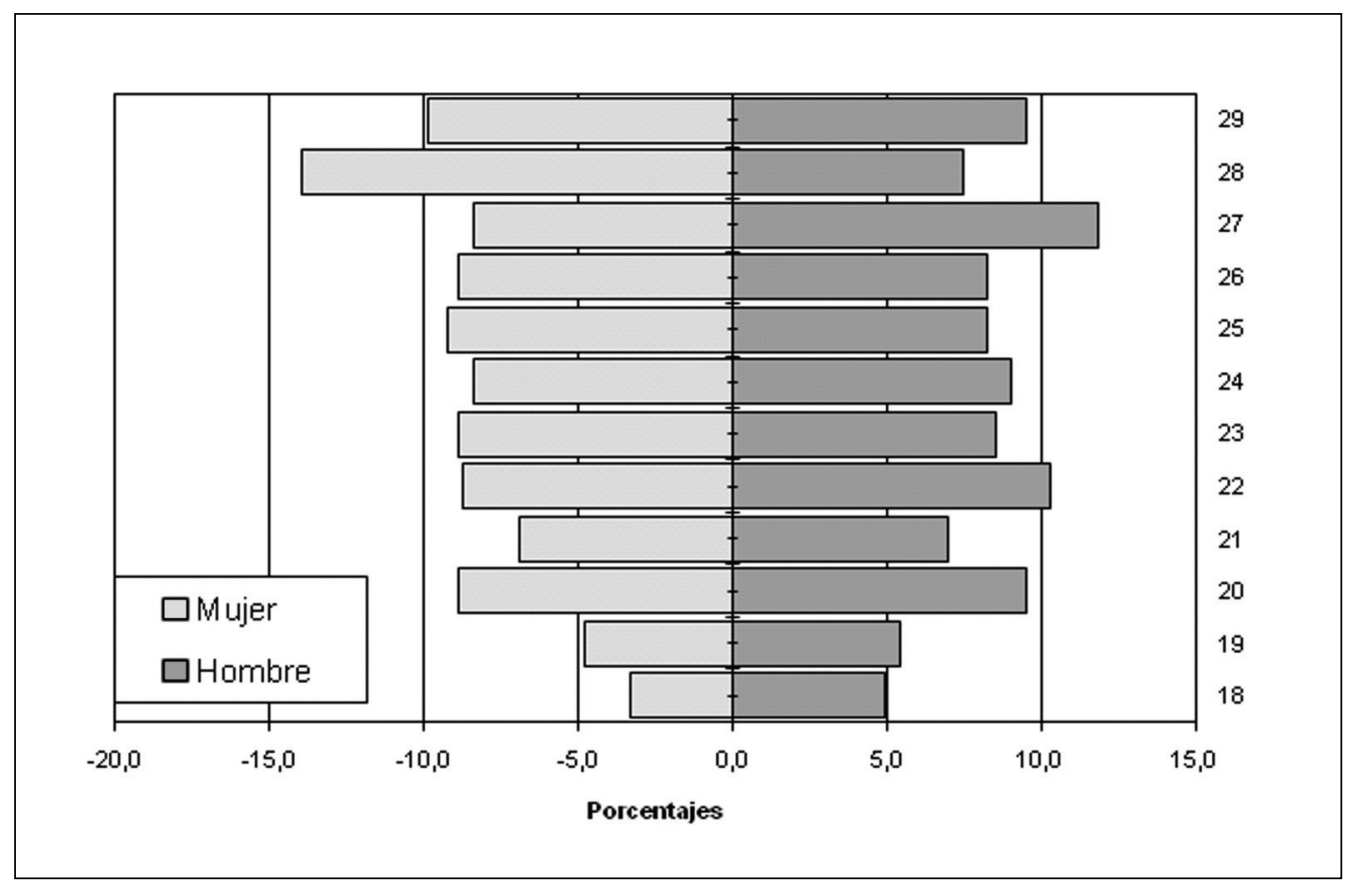

Gráfica 1. Distribución porcentual de las edades de los jóvenes mexicanos por sexo Fuente: Cálculos propios a partir de la ENCUP 2003. 
Cerca de la mitad de los jóvenes de 18 a 29 años (44.5\%) son casados, y el 13.7\% unidos, sólo un $37.7 \%$ son solteros y alrededor de un $10 \%$ son divorciados, separados o viudos. El 31.2\% de las mujeres jóvenes no tiene hijos mientras que el $68.8 \%$ de estas, oscilan entre 1 y 6 hijos, predominando entre 1 y 2 hijos por mujer. Podría decirse que el estado civil y el número de hijos, pueden delinear un marco social de los jóvenes con diferentes problemas o necesidades sociales que hagan que sus prácticas o intensidad de la participación se vea modificada; en este sentido quisiéramos ver si el estado civil y el número de hijos determinan las prácticas de la participación ciudadana.

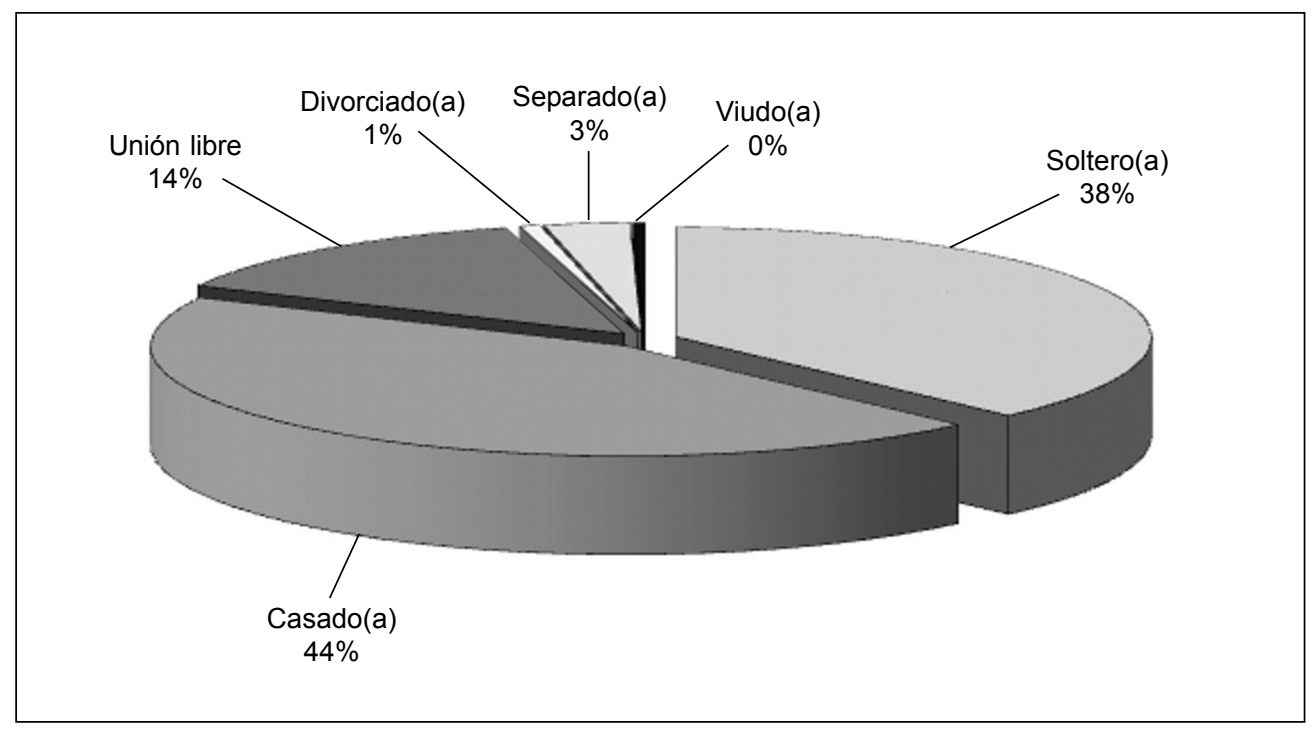

Gráfica 2: Distribución del estado civil de los jóvenes mexicanos Fuente: Cálculos propios a partir de la ENCUP 2003.

En cuanto al grado de escolaridad alcanzado por los jóvenes al momento de la encuesta, teniendo en cuenta que estos jóvenes aún se encuentran en edad escolar y que pueden llegar a alcanzar mejores niveles, se observa un promedio de escolaridad entre primaria terminada y secundaria incompleta, encontrando un $2.7 \%$ que no sabe aún ni leer ni escribir, y un $0.2 \%$ sin instrucción, el $28.7 \%$ tiene primaria terminada, el 33.4\% tiene secundaria, $19.4 \%$ preparatoria y $15.4 \%$ licenciatura. Tomando la escolaridad como un factor que permite una mayor socialización del individuo con personas de su edad y con su entorno, a través del intercambio de información y que puede permitir un proceso de interacción con los problemas sociales y las formas de organización posibles para mejorar su situación, en este sentido, se considera que el grado de escolaridad alcanzado puede llegar a determinar las prácticas de diferentes formas de participación ciudadana. 
Otra característica del individuo que puede impactar en la participación ciudadana es la condición de actividad de los jóvenes, observando que dentro de las actividades más comunes se encontraron trabajando un 51.8\% de los jóvenes, en los quehaceres de la casa el 35.7\%, el 9\% es estudiante, y un 3.5\% no trabaja. Se esperaría que las aspiraciones de los jóvenes puedan llegar a influir en el interés por organizarse o vincularse a partidos u organizaciones que ayuden a alcanzar o mantener ciertas necesidades o aspiraciones de los jóvenes estimulando una mayor participación ciudadana.

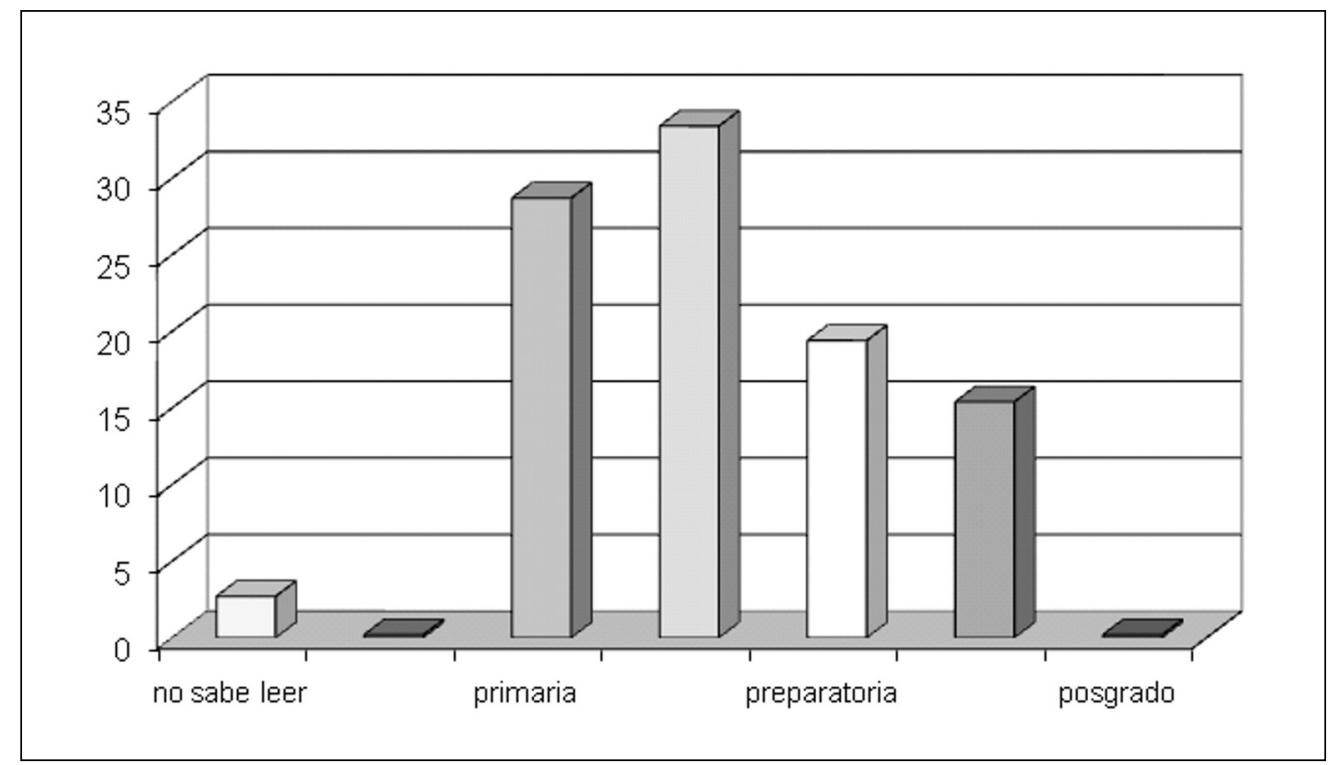

Gráfica 3: Distribución de la escolaridad de los jóvenes Fuente: Cálculos propios a partir de la ENCUP 2003.

Ahora bien, con una imagen del perfil de los jóvenes mexicanos y una vez expresadas las hipótesis de trabajo, analizaremos las formas de participación que tienen los jóvenes, con el fin de determinar después si las características sociodemográficas están influyendo en este tipo de prácticas.

\section{PRÁCTICAS DE PARTICIPACIÓN CIUDADANA DE LOS JÓVENES MEXICANOS EN LA MUESTRA DE LA ENCUP 2003.}

De acuerdo con las prácticas de participación ciudadana, se identificaron diversas formas de participación. Dentro de estas inicialmente analizamos 11 acciones de participación ciudadana no políticas (Tabla 2) descritas por los individuos como: Sí las realiza, y No las realiza. De estas 
acciones los jóvenes muestran en la mayoría una menor participación con respecto a los no jóvenes o considerados para el estudio como mayores, lo que podría estar influenciado por su menor edad. Dentro de las acciones o expresiones de participación que realizan los jóvenes en mayor proporción que los mayores aparecen: enviar o firmar cartas con un $21.6 \%$, enviar mensajes por computadora $7.2 \%$ y recaudar fondos con el $22 \%$, mostrando las tendencias o formas de preferencias de participación de los jóvenes. Sin embargo, las acciones más frecuentes que realizan los jóvenes son: Dar dinero a la Cruz Roja 80.1\% y auxiliar a algún desconocido 58.1\%.

Tabla 2. Acciones de Participación Ciudadana

\begin{tabular}{|c|c|c|c|c|c|c|c|c|}
\hline \multirow{2}{*}{$\begin{array}{c}\text { Alguna vez usted ha llevado } \\
\text { a cabo las siguientes acciones ...? }\end{array}$} & \multicolumn{4}{|c|}{ Jóvenes } & \multicolumn{4}{|c|}{ Mayores } \\
\hline & Sí & $\%$ & No & $\%$ & Sí & $\%$ & No & $\%$ \\
\hline ¿Donar sangre? & 171 & 17.2 & 825 & 82.7 & 1035 & 28.9 & 2534 & 70.7 \\
\hline ¿Dar dinero a la cruz roja? & 799 & 80.1 & 197 & 19.8 & 2987 & 83.4 & 583 & 16.3 \\
\hline $\begin{array}{l}\text { ¿Donar alimentos, medicinas, ropa en caso } \\
\text { de desastre? }\end{array}$ & 461 & 46.2 & 535 & 53.7 & 2007 & 56.0 & 1564 & 43.7 \\
\hline $\begin{array}{l}\text { ¿Participar como voluntario en alguna } \\
\text { actividad de beneficio para la comunidad? }\end{array}$ & 348 & 34.9 & 647 & 64.9 & 1534 & 42.8 & 2034 & 56.8 \\
\hline ¿Auxiliar a algún desconocido? & 579 & 58.1 & 417 & 41.8 & 2279 & 63.6 & 1290 & 36.0 \\
\hline $\begin{array}{l}\text { ¿Enviar dinero u objetos a programas de } \\
\text { televisión o radio? }\end{array}$ & 150 & 15.0 & 846 & 84.9 & 662 & 18.5 & 2907 & 81.1 \\
\hline ¿Enviar o firmar cartas? & 215 & 21.6 & 779 & 78.1 & 735 & 20.5 & 2834 & 79.1 \\
\hline $\begin{array}{l}\text { ¿Enviar mensajes por computadora en } \\
\text { apoyo? }\end{array}$ & 72 & 7.2 & 923 & 92.6 & 119 & 3.3 & 3449 & 96.3 \\
\hline ¿Participar en actos de apoyo? & 268 & 26.9 & 727 & 72.9 & 973 & 27.2 & 2595 & 72.4 \\
\hline ¿Recaudar fondos? & 219 & 22.0 & 775 & 77.7 & 774 & 21.6 & 2795 & 78.0 \\
\hline $\begin{array}{l}\text { ¿Dar donativos o prestar ayuda a } \\
\text { organizaciones sociales? }\end{array}$ & 197 & 19.8 & 798 & 80.0 & 862 & 24.1 & 2703 & 75.4 \\
\hline Participado con alguna acción & 909 & 91.2 & 88 & 8.8 & 3319 & 92.6 & 264 & 7.4 \\
\hline Participación Baja (al menos 4 acciones) & 699 & 70.1 & 298 & 29.9 & 2243 & 62.6 & 1340 & 37.4 \\
\hline Participación Alta (más de 5 acciones) & 298 & 29.9 & 699 & 70.1 & 1340 & 37.4 & 2243 & 62.6 \\
\hline
\end{tabular}

Fuente: Cálculos propios a partir de la ENCUP 2003. 
Analizando las 11 acciones en conjunto, encontramos que tan sólo un 8.8\% de los jóvenes responden no haber realizado alguna de las acciones. Sin embargo, observamos un $70.1 \%$ de los jóvenes con una baja participación (con al menos 4 acciones), y un $29.9 \%$ con una alta participación (con más de 5 acciones de participación ciudadana). Como dijimos anteriormente, esta situación puede estar condicionada por la menor edad, ya que un 4.7\% de ellos afirman no haber tenido la oportunidad o no haber sido invitados, aunque además un $2.9 \%$ manifiesta no haber tenido tiempo o interés y llama la atención un $0.7 \%$ que manifestó no tener confianza.

Los jóvenes que manifiestan percibir problemas en su comunidad y que están interesados en ayudar a resolverlos fueron de alrededor del $52.7 \%$, y los que hablan de los problemas de su comunidad de forma frecuente fueron el $20.6 \%$, algunas veces el $35.8 \%$ y nunca el $42 \%$. Dentro de los problemas que percibieron principalmente fueron: la inseguridad $11.8 \%$, el estado de las calles, caminos y vialidades $11 \%$, alumbrado público $4.3 \%$, agua potable $4.3 \%$ y drenaje $4.2 \%$, entre otros. En concordancia con lo anterior, los jóvenes mencionan que algunos de los problemas sociales que tienen y que podrían solucionarse con la participación ciudadana, son entre ellos: la seguridad pública $15.5 \%$, el estado de las calles, caminos y carreteras $9.3 \%$, la limpieza de áreas públicas y basura 5.9\% y el agua 5.1\%.

Uno de los mecanismos de participación ciudadana, cuando la comunidad percibe problemas sociales y están interesados en ayudar a resolverlos, ha sido tratar de organizarse socialmente. Para esto se midieron 14 estrategias para tratar de resolver problemas sociales, y dentro de ellas las más utilizadas por los jóvenes fueron: organizarse con otras personas afectadas $37.8 \%$, quejarse ante las autoridades $31.8 \%$ y firmar cartas de apoyo $20.6 \%$.

Generalmente, hemos visto que las personas mayores tienen una mayor participación ciudadana, observando que al menos un 55.5\% ha tratado alguna forma de organización para resolver problemas comunes, con respecto a los jóvenes que trataron al menos una forma un $45.6 \%$. Sin embargo, en estas estrategias de organización se perciben algunas que son más utilizadas por los jóvenes que por los mayores, entre ellas están: firmar cartas de apoyo $20.6 \%$, pedir apoyo a alguna organización civil $12.6 \%$, promover una idea de forma pacífica $9.7 \%$, llamar a un programa de radio o televisión $9.1 \%$ y repartir circulares o manifiestos con el $6.4 \%$ (Tabla 3).

De acuerdo con las formas de organización, con respecto a formar o haber formado parte de diversas organizaciones en algún momento de su vida, encontramos que los jóvenes participaron principalmente en organizaciones tales como agrupaciones religiosas $25.3 \%$, organizaciones de vecinos $13 \%$ y organizaciones de ciudadanos $10.5 \%$. En general, se observa una participación menor de los jóvenes en al menos una de las formas de organización, 45.6\% con respecto a los mayores con un 55.5\% en promedio. Sin embargo, se presenta una mayor participación de los jóvenes en aspectos tales como organizaciones de arte y cultura con un $5.7 \%$ y en otros grupos organizados $1.9 \%$, con respecto a los mayores que presentaron un $4.7 \%$ y $1.7 \%$ respectivamente (Tabla 4 ). 
Tabla 3. Participación para resolver problemas

\begin{tabular}{|c|c|c|c|c|c|c|c|c|}
\hline \multirow{2}{*}{$\begin{array}{l}\text { Para resolver un problema } \\
\text { que afecta a Usted y a otras personas, } \\
\text { Alguna vez ha tratado de ...? }\end{array}$} & \multicolumn{4}{|c|}{ Jóvenes } & \multicolumn{4}{|c|}{ Mayores } \\
\hline & Sí & $\%$ & No & $\%$ & Sí & $\%$ & No & $\%$ \\
\hline ¿Organizarse con otras personas afectadas? & 377 & 37.8 & 620 & 62.2 & 1490 & 41.6 & 2093 & 58.4 \\
\hline ¿Mandar cartas al periódico? & 57 & 5.7 & 940 & 94.3 & 257 & 7.2 & 3326 & 92.8 \\
\hline ¿Quejarse ante las autoridades? & 317 & 31.8 & 680 & 68.2 & 1190 & 33.2 & 2393 & 66.8 \\
\hline ¿Pedir apoyo a alguna organización civil? & 126 & 12.6 & 871 & 87.4 & 434 & 12.1 & 3149 & 87.9 \\
\hline Asistir a manifestaciones & 91 & 9.1 & 906 & 90.9 & 470 & 13.1 & 3113 & 86.9 \\
\hline Solicitar apoyo de un partido político & 114 & 11.4 & 883 & 88.6 & 460 & 12.8 & 3123 & 87.2 \\
\hline Pedir ayuda a diputados o senadores & 53 & 5.3 & 944 & 94.7 & 284 & 7.9 & 3299 & 92.1 \\
\hline $\begin{array}{l}\text { ¿Llamar a un programa de radio o } \\
\text { televisión? }\end{array}$ & 91 & 9.1 & 906 & 90.9 & 281 & 7.8 & 3302 & 92.2 \\
\hline ¿Escribir al presidente o las autoridades? & 86 & 8.6 & 911 & 91.4 & 360 & 10.0 & 3223 & 90.0 \\
\hline ¿Firmar cartas de apoyo? & 205 & 20.6 & 792 & 79.4 & 725 & 20.2 & 2858 & 79.8 \\
\hline ¿Colocar mantas, carteles o fotografías? & 53 & 5.3 & 944 & 94.7 & 189 & 5.3 & 3394 & 94.7 \\
\hline ¿Repartir circulares o manifiestos? & 64 & 6.4 & 933 & 93.6 & 176 & 4.9 & 3407 & 95.1 \\
\hline ¿Promover una idea de forma pacífica & 97 & 9.7 & 900 & 90.3 & 319 & 8.9 & 3264 & 91.1 \\
\hline Otra & 4 & 0.4 & 993 & 99.6 & 25 & 0.7 & 3558 & 99.3 \\
\hline Ha tratado al menos una & 455 & 45.6 & 542 & 54.4 & 1989 & 55.5 & 1594 & 44.5 \\
\hline
\end{tabular}

Fuente: Cálculos propios a partir de la ENCUP 2003.

Contrastando la participación de los jóvenes en al menos una de las formas de organización (45.6\%), con la asistencia a este tipo de organizaciones en el último año (59\%), encontramos una mayor participación de los jóvenes mediante la asistencia a este tipo de organizaciones en el último año, ratificando la vinculación a las formas de organización y mostrando un mayor compromiso en los últimos tiempos.

Se observan las preferencias de los jóvenes por asistir a reuniones de la asociación de padres de familia de la escuela con un 30.8\%, aunque aquí no se aclara si es en calidad de estudiante o de padre de familia, en lo cual se considera puede haber de parte y parte. Se confirma también las preferencias por participar en las reuniones de actividades religiosas con un $29.4 \%$ de participación, así como un 21.8\% de los jóvenes participó en las Juntas de vecinos (Tabla 5). 
Tabla 4. Participación en Organizaciones

\begin{tabular}{|l|cccc|cccc|}
\hline \multirow{2}{*}{$\begin{array}{c}\text { ¿Usted forma o ha formado parte de } \\
\text { alguna de las siguientes organizaciones ...? }\end{array}$} & \multicolumn{4}{|c|}{ Jóvenes } & \multicolumn{4}{c|}{ Mayores } \\
\cline { 2 - 9 } & Sí & \% & No & \% & Sí & \% & No & \% \\
\hline Sindicato & 86 & 8.6 & 911 & 91.4 & 574 & 16.0 & 3009 & 84.0 \\
Partido político & 71 & 7.1 & 926 & 92.9 & 476 & 13.3 & 3107 & 86.7 \\
Agrupaciones profesionales & 30 & 3.0 & 967 & 97.0 & 176 & 4.9 & 3407 & 95.1 \\
Cooperativas & 70 & 7.0 & 927 & 93.0 & 304 & 8.5 & 3279 & 91.5 \\
Agrupaciones políticas & 43 & 4.3 & 954 & 95.7 & 267 & 7.5 & 3316 & 92.5 \\
Instituciones de beneficencia & 48 & 4.8 & 949 & 95.2 & 253 & 7.1 & 3330 & 92.9 \\
Agrupaciones religiosas & 252 & 25.3 & 745 & 74.7 & 972 & 27.1 & 2611 & 72.9 \\
Organizaciones de ciudadanos & 105 & 10.5 & 892 & 89.5 & 569 & 15.9 & 3014 & 84.1 \\
Agrupaciones de ayuda social & 79 & 7.9 & 918 & 92.1 & 330 & 9.2 & 3253 & 90.8 \\
Organizaciones de Vecinos & 130 & 13.0 & 867 & 87.0 & 748 & 20.9 & 2835 & 79.1 \\
Pensionados y jubilados & 11 & 1.1 & 986 & 98.9 & 180 & 5.0 & 3403 & 95.0 \\
Arte y Cultura & 57 & 5.7 & 940 & 94.3 & 169 & 4.7 & 3414 & 95.3 \\
Otros grupos organizados & 19 & 1.9 & 978 & 98.1 & 61 & 1.7 & 3522 & 98.3 \\
\hline Participado en alguna organización & $\mathbf{4 5 5}$ & $\mathbf{4 5 . 6}$ & $\mathbf{5 4 2}$ & $\mathbf{5 4 . 4}$ & $\mathbf{1 9 8 9}$ & $\mathbf{5 5 . 5}$ & $\mathbf{1 5 9 4}$ & $\mathbf{4 4 . 5}$ \\
\hline
\end{tabular}

Fuente: Cálculos propios a partir de la ENCUP 2003.

Por último, una de las formas más visibles de participación ciudadana, ha sido el ejercicio del derecho a votar o a elegir al candidato por el cual será representado; en este sentido, el $64 \%$ de los jóvenes manifestaron haber acudido a votar desde el 2000 en al menos una de las 6 elecciones indagadas, donde principalmente se observó el interés de los jóvenes por acudir a las elecciones presidenciales de un 59\% y en las de presidentes municipales del $53.9 \%$, aunque en general hubo una participación similar. Por las que menos interés presentaron fue en la elección de los diputados locales $47.3 \%$ y en los Gobernadores de Estado $47.6 \%$ (Tabla 6).

En este sentido, los datos de la muestra de la ENCUP 2003, muestran diferencias sustanciales que se consideran de relevancia para el armado de los modelos. Sin embargo, una mirada a los datos expandidos, permiten ver los contrastes referidos. Para ello nos detendremos a observar la distribución de la población total y la que participa en al menos una de las acciones de participación ciudadana y electoral, usando las pirámides demográficas y luego construyendo la gráfica comparativa entre ambas formas de participación. 
Tabla 5. Participación en organizaciones en el último año

\begin{tabular}{|c|c|c|c|c|c|c|c|c|}
\hline \multirow{2}{*}{$\begin{array}{c}\text { ¿Durante el último año, asistió } \\
\text { a alguna reunión de las siguientes } \\
\text { organizaciones ...? }\end{array}$} & \multicolumn{4}{|c|}{ Jóvenes } & \multicolumn{4}{|c|}{ Mayores } \\
\hline & Sí & $\%$ & No & $\%$ & Sí & $\%$ & No & $\%$ \\
\hline Junta de Vecinos & 217 & 21.8 & 780 & 78.2 & 1152 & 32.2 & 2431 & 67.8 \\
\hline Junta de Colonos & 116 & 11.6 & 881 & 88.4 & 713 & 19.9 & 2870 & 80.1 \\
\hline Agrupación y organización de ciudadanos & 86 & 8.6 & 911 & 91.4 & 466 & 13.0 & 3117 & 87.0 \\
\hline Asamblea de la ciudad & 179 & 18.0 & 818 & 82.0 & 992 & 27.7 & 2591 & 72.3 \\
\hline Organizaciones de autoayuda & 46 & 4.6 & 951 & 95.4 & 242 & 6.8 & 3341 & 93.2 \\
\hline Asociación de padres de familia & 307 & 30.8 & 690 & 69.2 & 1582 & 44.2 & 2001 & 55.8 \\
\hline Reuniones de actividades religiosas & 293 & 29.4 & 704 & 70.6 & 1208 & 33.7 & 2375 & 66.3 \\
\hline Algún partido o grupo político & 54 & 5.4 & 943 & 94.6 & 402 & 11.2 & 3181 & 88.8 \\
\hline Sindical & 46 & 4.6 & 951 & 95.4 & 304 & 8.5 & 3279 & 91.5 \\
\hline Cooperativas o asamblea ejidal & 50 & 5.0 & 947 & 95.0 & 331 & 9.2 & 3252 & 90.8 \\
\hline Asamblea de miembros de cajas de ahorro & 25 & 2.5 & 972 & 97.5 & 145 & 4.0 & 3438 & 96.0 \\
\hline Otra & 7 & 0.7 & 990 & 99.3 & 34 & 0.9 & 3549 & 99.1 \\
\hline Asistido al menos a una en el año & 588 & 59.0 & 409 & 41.0 & 2552 & 71.2 & 1031 & 28.8 \\
\hline
\end{tabular}

Fuente:Cálculos propios a partir de la ENCUP 2003.

Tabla 6. Participación electoral

\begin{tabular}{|l|cccc|cccc|}
\hline \multirow{2}{*}{$\begin{array}{l}\text { ¿Del año 2000 a la fecha, acudió a votar en } \\
\text { algunas de las siguientes elecciones...? }\end{array}$} & \multicolumn{4}{|c|}{ Jóvenes } & \multicolumn{4}{c|}{ Mayores } \\
\cline { 2 - 9 } & Sí & \% & No & \% & Sí & \% & No & \% \\
\hline Presidente de la República & 588 & 59.0 & 409 & 41.0 & 2939 & 82.0 & 644 & 18.0 \\
Senadores & 491 & 49.2 & 506 & 50.8 & 2615 & 73.0 & 968 & 27.0 \\
Diputados Federales & 485 & 48.6 & 512 & 51.4 & 2622 & 73.2 & 961 & 26.8 \\
Gobernador del Estado & 475 & 47.6 & 522 & 52.4 & 2489 & 69.5 & 1094 & 30.5 \\
Presidente Municipal & 537 & 53.9 & 460 & 46.1 & 2776 & 77.5 & 807 & 22.5 \\
Diputados Locales & 472 & 47.3 & 525 & 52.7 & 2538 & 70.8 & 1045 & 29.2 \\
\hline Ha votado en al menos una & $\mathbf{6 3 9}$ & $\mathbf{6 4 . 1}$ & $\mathbf{3 5 8}$ & $\mathbf{3 5 . 9}$ & $\mathbf{3 0 8 1}$ & $\mathbf{8 6 . 0}$ & $\mathbf{5 0 2}$ & $\mathbf{1 4 . 0}$ \\
\hline
\end{tabular}

Fuente: Cálculos propios a partir de la ENCUP 2003. 


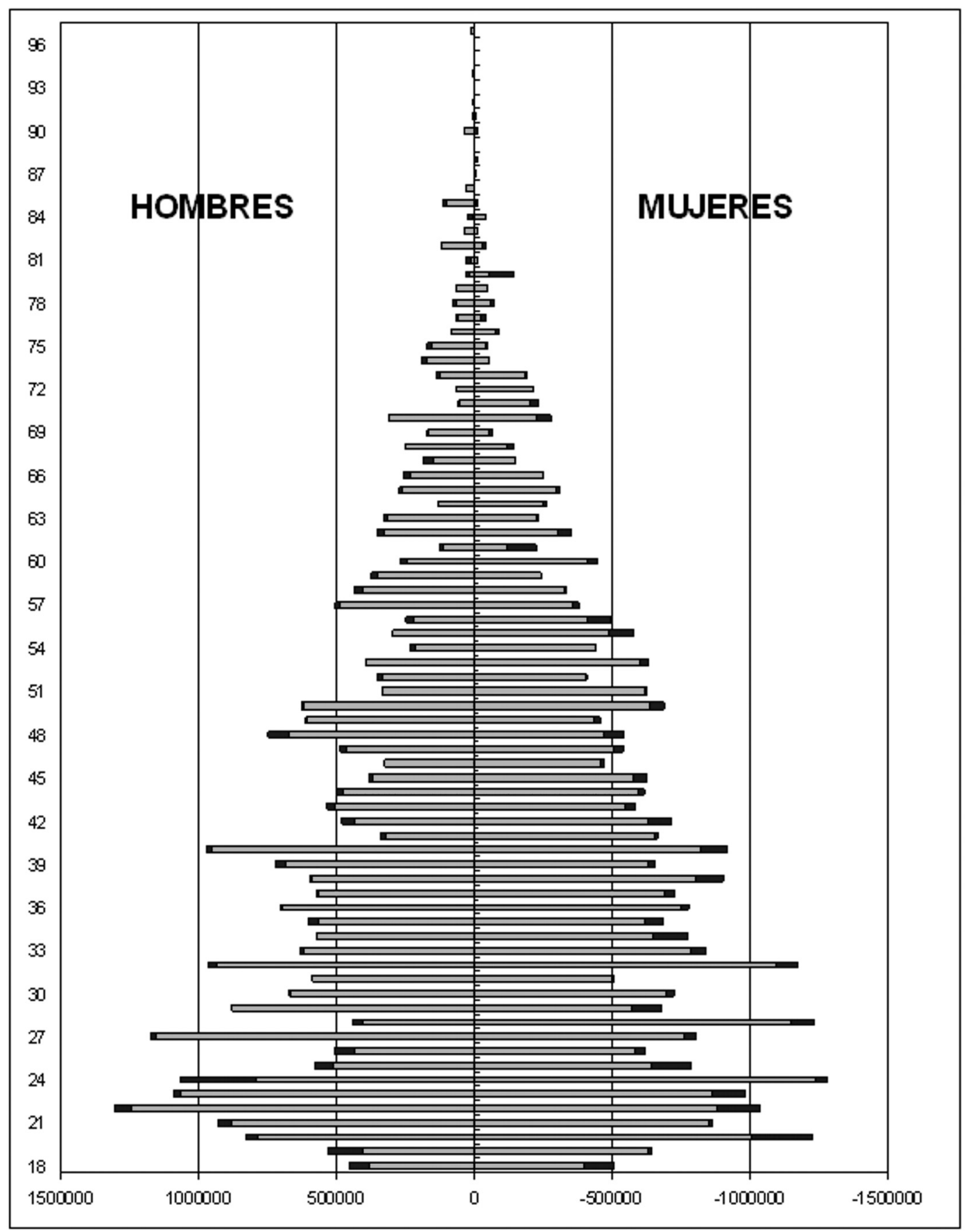

Gráfica 4. Pirámide de población de la participación en acciones sociales, edades simples, 2003 (Datos expandidos)

Fuente: Cálculos propios a partir de la ENCUP 2003. Azul, población total de la muestra expandida y en rojo la participación en acciones sociales. 


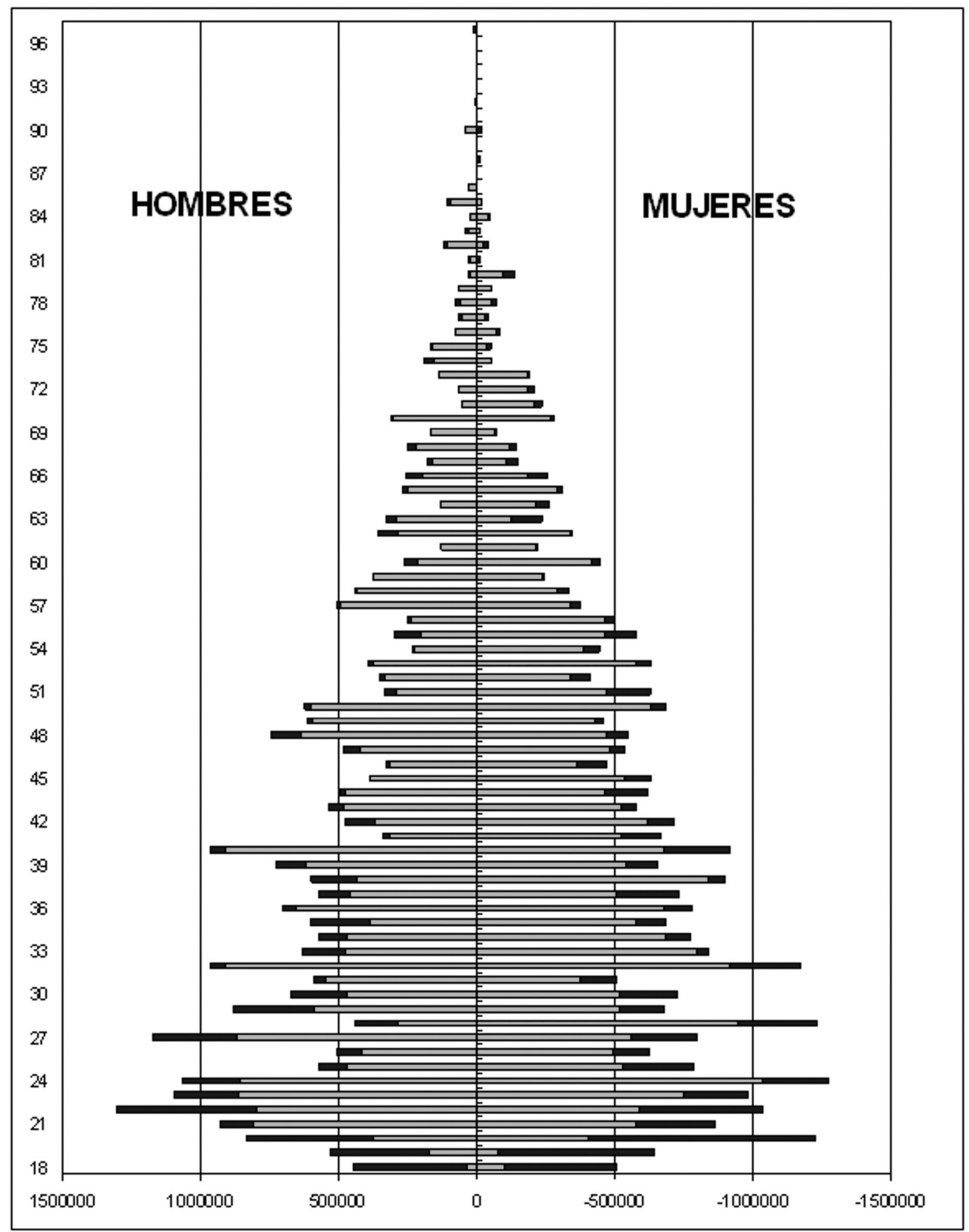

Gráfica 5. Pirámide de población de la participación en elecciones, edades simples, 2003 (Datos expandidos)

Fuente: Cálculos propios a partir de la ENCUP 2003. Azul, población total de la muestra expandida y en rojo la participación en elecciones. 
Las pirámides de población de las gráficas 4 y 5, muestran claramente que la población en México tiene una alta capacidad de participación en acciones de ciudadanía, lo cual es un fenómeno generalizado tanto por sexo como por edades, aun cuando las mujeres tienen menor proporción de participación que la de los hombres. Los jóvenes muestran tener menor participación en acciones de ciudadanía, y en este grupo de la población, se puede apreciar que persisten las diferencias de participación entre hombres y mujeres.

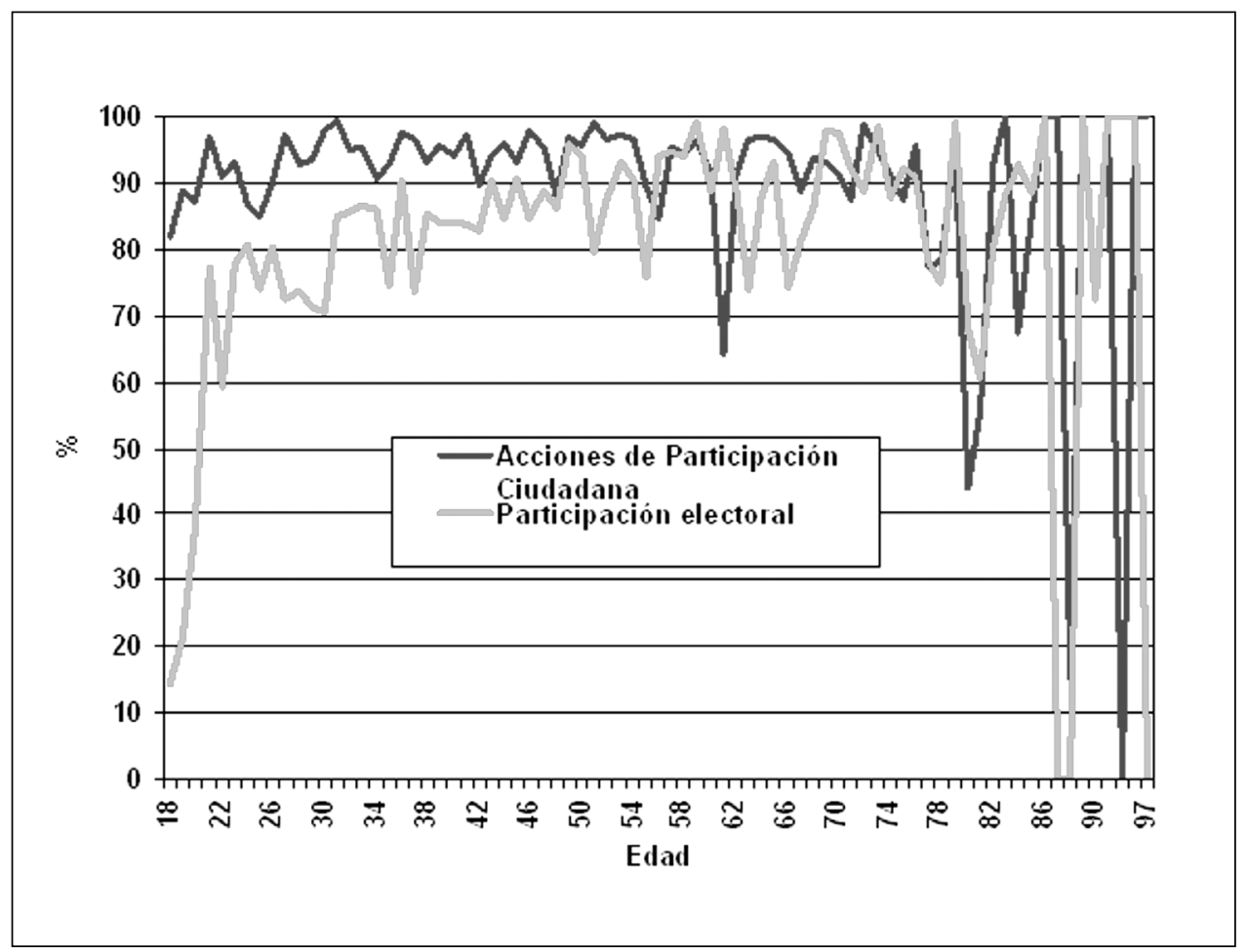

Gráfica 6. Distribución de la participación en acciones sociales y en elecciones, según edades simples, 2003 (Datos expandidos)

Fuente: Cálculos propios a partir de la ENCUP 2003.

Para el caso de la participación electoral, la pirámide de población cambia sustancialmente y se aprecia una generalizada contracción, siendo mucho más fuerte entre las mujeres y especialmente entre los jóvenes. Esto significa que existen fundamentos para pensar que el cambio generacional en el sistema democrático en México debería acompañarse con procesos de mayor incorporación de los jóvenes a la vida democrática del país, además del fortalecimiento de la transparencia a las instituciones democráticas para incentivar la credibilidad de la población 
joven que generacionalmente tiene mayor escolaridad y mayor capacidad de cuestionar las propuestas electorales que las anteriores.

Con esta información se construyó la gráfica 6, que muestra la proporción porcentual de la participación en acciones ciudadanas y electorales por edades simples. En ella nuevamente se aprecia que la población joven tiene niveles similares de participación en acciones ciudadanas que las registradas por los mayores, en tanto que, en la participación electoral, su proporción guarda una relación positiva con la edad. Esto decir que va aumentando a medida que se incrementa la edad. La variabilidad es mayor después de los sesenta años, que se comprende por el efecto demográfico dentro de la población y sus actividades sociales.

\section{ANÁLISIS MULTIVARIADO DE LA RELACIÓN ENTRE CONDICIONES SOCIOECONÓMICAS Y PARTICIPACIÓN CIUDADANA DE LOS JÓVENES MEXICANOS}

A continuación, se realizará un análisis mutivariado para condensar en un modelo los resultados hasta el momento obtenidos, retomando la metodología en Winocur y Horbath (2002: 483) y concentrándonos en identificar los posibles determinantes sociodemográficos de la participación ciudadana de los jóvenes mexicanos.

Para establecer la probabilidad de que ocurra el evento, tal que los individuos tengan una alta o baja participación respecto a sus características propias y a algunas de las características de los espacios de asociación, se hizo uso del Análisis de Regresión Logística (Hosmer y Lemeshow, 2000:92-116). De esta manera, la formulación del modelo logístico que relaciona la razón entre las probabilidades de ocurrencia y no ocurrencia del evento "Tener una alta participación" viene dada por la siguiente expresión:

$$
\log \left(\frac{\prod \omega}{\prod \varphi}\right)=B_{0}+B_{1} X_{1}+\ldots+B_{p} X_{p}
$$

Donde $\prod_{\boldsymbol{\omega}}$ ' es la probabilidad de que ocurra el evento "tener una alta participación" y el denominador del fraccionario $\prod_{\varphi}$ es la probabilidad de que no ocurra el evento.

Al repetir la anterior ecuación quedaría así:

$$
\frac{\prod \omega}{\prod \varphi}=e^{B_{0}+B_{1} X_{1}+\ldots+B_{p} X_{p}}=e^{B_{0}} e^{B_{1} X_{1}} \ldots e^{B_{p} X_{p}}
$$


En ella, la probabilidad de "ocurrencia del evento" se expresaría como:

$$
\prod \omega=\frac{e^{B_{0}+B_{1} X_{1}+\ldots+B_{p} X_{p}}}{1+e^{B_{0}+B_{1} X_{1}+\ldots+B_{p} X_{p}}}=\frac{1}{1+e^{-\left(B_{0}+B_{1} X_{1}+\ldots+B_{p} X_{p}\right)}}
$$

Y la probabilidad de "no ocurrencia del evento" sería:

$$
\prod \varphi=1-\prod \omega
$$

Las variables que se seleccionaron para modelar como determinantes de la participación ciudadana fueron las siguientes:

\section{a. Variables Dependientes: (Dicotómicas) Indicadores resúmenes de la participación ciudadana}

Participación en acciones sociales: Se construyó el indicador con las respuestas a las siguientes preguntas: ¿Alguna vez ha llevado a cabo las siguientes acciones? Ha donado sangre, ha donado dinero a la cruz roja, ha donado alimentos, medicina, ropa en caso de un desastre, ha participado personalmente como voluntario en alguna actividad de beneficio para la comunidad, ha auxiliado a algún desconocido, ha enviado dinero u objetos a algún programa de televisión o radio para una buena causa, ha enviado o firmado cartas para una buena causa, ha enviado mensajes por computadora en apoyo de alguna causa, ha participado en actos de apoyo a alguna causa, ha recaudado fondos para una causa, ha hecho donativos o prestado ayuda a alguna organización social.

Las respuestas posibles fueron: Sí, No, No sabe, No contesta. El contenido de las respuestas: No sabe, No contesta, no superó el 1\%, así que esta variable se dicotomizó en 1.Sí y 0. No, se generó un índice resumen de la suma de las variables anteriores, generando un indicador con resultados de 0 a 11, siendo 0 los que no participaron en ninguna de las anteriores acciones y a mayor valor, mayor participación. Por último el indicador se trabajó dicotómico: 1 Baja participación, con los que participaron en al menos cuatro acciones y 2 Alta participación, los que realizaron de 5 a 11 acciones de participación.

Participación Electoral: Se construyó el indicador con las respuestas a las siguientes preguntas: Del año 2000 a la fecha, zacudió a votar en algunas de las siguientes elecciones?: Presidente de la República; Senadores; Diputados Federales; Gobernador del Estado (o jefe de Gobierno en el caso del D.F.); Presidente Municipal (o jefe Delegacional en el caso del D.F.); Diputados Locales (o Asamblea Legislativa en el caso del D.F.). 


\section{b. Variables Independientes}

\section{Características del Individuo:}

Sexo: $\quad 1$ Hombre 2 Mujer

Edad: $\quad$ Grupos de edad 1 Jóvenes de 18 a 24 años, 2 Jóvenes Adultos de 25 a 29 años de edad

Grado de Esc: 1 No sabe leer 2 Sin instrucción 3 Primaria 4 Secundaria 5 Preparatoria 6 Licenciatura 7 Postgrado

Estado Civil: 1 Soltero(a) 2 Casado(a) 3 Unión Libre 4 Divorciado(a) 5 Separado(a) 6 Viudo(a)

Discapacidad: 1 Movilidad 2 Visual 3 Física ó Mental 4 Ninguna

Hijos: $\quad 1$ No tiene 2 Número de Hijos 3 No sabe

\section{Características del empleo:}

Condición

de Actividad: 1 Trabajo 2 No trabajo, pero si tiene trabajo 3 Buscó Trabajo 4 Estudiante 5 Se dedica a los quehaceres del hogar 6 Está incapacitado permanentemente para trabajar 7 No trabajo porque ya no tiene trabajo 8 Ocioso voluntario

Ocupación: 1 Profesionistas o técnico 2 Funcionarios de los sectores privado y público 3 personal administrativo 4 Comerciantes, vendedores y similares 5 Trabajadores en servicios personales y conductores vehiculares 6 Trabajadores en labores agropecuarias 7 Trabajadores industriales 8 No especificado

Rama: $\quad 1$ Sector Agropecuario 2 Industria de la información 3 Construcción 4 Comercio 5 Servicios 6 Administración y Transporte 7 Administración pública y defensa 8 No especificado.

6 Trabajador sin pago 7 No sabe

Ingresos: $\quad$ Ingreso mensual del joven (Continua)

\section{Características Regionales:}

Zona: $\quad 1$ Áreas más urbanizadas (100 Mil y +), 2 Áreas menos urbanizadas (15 Y $99 \mathrm{mil}), 3$ Áreas rurales (Menos de $15 \mathrm{mil}$ )

Región: $\quad 1$ Noreste, 2 Noroeste, 3 Occidente, 4 Centro, 5 Sur-sureste.

Marginación: Grado de Marginación del 2000; 1 Muy Alto, 2 Alto, 3 Medio, 4 Bajo, 5 Muy Bajo

Índice de

Desarrollo

Humano: 1 Alto Grado, Medio Grado, Bajo Grado. 
El análisis incorporó un total de 997 registros de la base de datos de la encuesta ENCUP 2003, los cuales hacen referencia a los jóvenes de 18 a 29 años de edad. El modelo se construyó a partir del Método de selección por pasos hacia adelante que contrasta la entrada basándose en la significación del estadístico de puntuación y contrasta la eliminación basándose en la probabilidad del estadístico de Wald. Las covariables categóricas fueron ingresadas con contraste polinómico con la primera categoría de referencia en cada una de ellas.

\section{RESULTADOS DEL MODELO DE PARTICIPACIÓN CIUDADANA DE LOS JÓVENES.}

Los resultados mostraron una parsimonia del modelo dado que incluyó solamente tres variables, dos de ellas con una confianza del $99 \%$ y solamente la variable sexo que por razones de diferenciación se amplió la confianza hasta un 90\% para que ingresara al modelo (Tabla 7).

\section{Tabla 7. Modelo de Participación en acciones sociales}

\begin{tabular}{|c|c|c|c|c|c|c|c|c|}
\hline \multirow{2}{*}{$\begin{array}{l}\text { Variables en } \\
\text { la ecuación }\end{array}$} & \multirow{2}{*}{ B } & \multirow{2}{*}{ E.T. } & \multirow{2}{*}{ Wald } & \multirow{2}{*}{ Gl. } & \multirow{2}{*}{ Sig. } & \multirow{2}{*}{$\operatorname{Exp}(B)$} & \multicolumn{2}{|c|}{ I.C. $95.0 \%$ para EXP(B) } \\
\hline & & & & & & & Inferior & Superior \\
\hline Constante & -1.199 & 0.115 & 108.219 & 1 & 0.000 & 0.302 & & \\
\hline ESCOLA & & & 34.441 & 4 & 0.000 & & & \\
\hline $\operatorname{ESCOLA}(1)$ & -2.768 & 0.864 & 10.258 & 1 & 0.001 & 0.063 & 0.012 & 0.342 \\
\hline $\operatorname{ESCOLA}(2)$ & -2.154 & 0.421 & 26.23 & 1 & 0.000 & 0.116 & 0.051 & 0.265 \\
\hline $\operatorname{ESCOLA}(3)$ & -1.757 & 0.413 & 18.129 & 1 & 0.000 & 0.173 & 0.077 & 0.387 \\
\hline $\operatorname{ESCOLA}(4)$ & -0.924 & 0.447 & 4.278 & 1 & 0.039 & 0.397 & 0.165 & 0.953 \\
\hline SEXO(1) & 0.665 & 0.258 & 6.628 & 1 & 0.010 & 1.944 & 1.172 & 3.224 \\
\hline REGION & & & 15.352 & 4 & 0.004 & & & \\
\hline REGION(1) & 0.447 & 0.484 & 0.853 & 1 & 0.356 & 1.563 & 0.606 & 4.035 \\
\hline REGION(2) & 2.371 & 0.622 & 14.517 & 1 & 0.000 & 10.706 & 3.162 & 36.248 \\
\hline REGION(3) & 0.355 & 0.303 & 1.37 & 1 & 0.242 & 1.426 & 0.787 & 2.586 \\
\hline REGION(4) & 0.596 & 0.374 & 2.544 & 1 & 0.111 & 1.815 & 0.873 & 3.774 \\
\hline \multicolumn{2}{|c|}{ Incluidos en el análisis } & & 423 & \multicolumn{3}{|c|}{-2 log de la verisimilitud } & & 393.118 \\
\hline \multicolumn{2}{|l|}{ Casos perdidos } & & 574 & \multicolumn{3}{|c|}{ R cuadrado de Cox y Snell } & & 0.142 \\
\hline \multicolumn{2}{|l|}{ Total } & & 997 & \multicolumn{3}{|c|}{ R cuadrado de Nagelkerke } & & 0.215 \\
\hline
\end{tabular}

Fuente: Cálculos propios a partir de la ENCUP 2003.

La variabilidad de la probabilidad de una participación alta a una participación baja en diferentes acciones sociales es baja, dado que solamente logra explicar un $21.5 \%$ del modelo. Sin embargo, esta explicación puede ser significativa en los estudios de participación ciudadana. 
El modelo muestra como variables asociadas a las acciones sociales de participación ciudadana algunas características de las personas, como son su grado de escolaridad y el sexo y características regionales como la región donde residen.

La escolaridad se ve relacionada con las acciones de participación ciudadana en la medida en que al aumentar el grado de escolaridad de los jóvenes hasta el nivel de preparatoria, este induce a una mayor participación, comparado con la de los jóvenes que no saben leer ni escribir.

Igualmente, diferenciando los jóvenes por sexo, con un 90\% de confianza podemos decir que las mujeres participan en acciones sociales en casi el doble con respecto a los hombres, lo cual puede explicarse por la calidad humana de las mujeres y el rol social de participar en acciones sociales como las medidas en el estudio.

En las características regionales, vemos un diferencial de la participación en acciones sociales por regiones, tomando como comparación la región noroeste, la cual es significante al compararla con la región occidente en donde se ve una participación 9.7 veces mayor con respecto a los jóvenes del noreste.

Tabla 8. Modelo de Participación electoral

\begin{tabular}{|c|c|c|c|c|c|c|c|c|}
\hline \multirow{2}{*}{$\begin{array}{l}\text { Variables en la } \\
\text { ecuación }\end{array}$} & \multirow{2}{*}{ B } & \multirow{2}{*}{ E.T. } & \multirow{2}{*}{ Wald } & \multirow{2}{*}{ Gl. } & \multirow{2}{*}{ Sig. } & \multirow{2}{*}{$\operatorname{Exp}(B)$} & \multicolumn{2}{|c|}{ I.C. $95.0 \%$ para EXP(B) } \\
\hline & & & & & & & Inferior & Superior \\
\hline Constante & 0.579 & 0.066 & 77.012 & 1 & 0.000 & 1.785 & & \\
\hline EDAD & 0.208 & 0.023 & 81.94 & 1 & 0.000 & 1.232 & 1.177 & 1.289 \\
\hline ESCOLA & & & 41.598 & 6 & 0.000 & & & \\
\hline ESCOLA(1) & 0.754 & 1.481 & 0.259 & 1 & 0.611 & 2.126 & 0.117 & 38.744 \\
\hline $\operatorname{ESCOLA}(2)$ & 5.693 & 9.646 & 0.348 & 1 & 0.555 & 296.72 & 0 & $4.8155 E+10$ \\
\hline $\operatorname{ESCOLA}(3)$ & 0.899 & 1.431 & 0.395 & 1 & 0.530 & 2.458 & 0.149 & 40.58 \\
\hline $\operatorname{ESCOLA}(4)$ & 1.293 & 1.43 & 0.817 & 1 & 0.366 & 3.644 & 0.221 & 60.144 \\
\hline $\operatorname{ESCOLA}(5)$ & 1.852 & 1.437 & 1.66 & 1 & 0.198 & 6.37 & 0.381 & 106.533 \\
\hline $\operatorname{ESCOLA}(6)$ & 2.255 & 1.441 & 2.45 & 1 & 0.118 & 9.539 & 0.566 & 160.738 \\
\hline RESOLVER(1) & -0.368 & 0.142 & 6.717 & 1 & 0.010 & 0.692 & 0.524 & 0.914 \\
\hline \multicolumn{3}{|c|}{ Incluidos en el análisis } & 997 & \multicolumn{3}{|c|}{-2 log de la verisimilitud } & & 1171.903 \\
\hline \multicolumn{3}{|l|}{ Casos perdidos } & 0 & \multicolumn{4}{|c|}{ R cuadrado de Cox y Snell } & 0.122 \\
\hline \multicolumn{3}{|l|}{ Total } & 997 & \multicolumn{4}{|c|}{ R cuadrado de Nagelkerke } & 0.168 \\
\hline
\end{tabular}

Fuente: Cálculos propios a partir de la ENCUP 2003. 
En el modelo de participación electoral, igualmente ingresaron pocas de las variables de estudio, mostrando el indicador de participación electoral con una confianza del 90\%. Asociación con tres variables: la edad, la escolaridad y la capacidad de las personas para organizarse ante un problema.

La edad fue una variable que se introdujo al modelo de forma continua, en este sentido observamos que a mayor edad, empezando a los 19 años y comparado con la participación a los 18 años, se presenta una probabilidad 1.23 mayor de participar en elecciones aumentando hasta los 29 años.

La escolaridad es una característica que influye en la participación electoral de los jóvenes, aunque los grados de escolaridad comparados no salieron significativos, podríamos decir que hay una relación entre la participación electoral y el grado de escolaridad.

La participación electoral de los jóvenes también se ve asociada con la capacidad de los jóvenes de resolver problemas en la medida en que expresen haber tratado de conformar organizaciones para solucionar problemas de su comunidad; así este tipo de prácticas pueden predecir comportamientos relacionados con la participación electoral.

\section{CONCLUSIONES}

Los resultados de la ENCUP 2003 y siguientes, muestran que se han incorporado esfuerzos importantes por incorporar los conceptos expresados en el análisis previo que se realizó por Winocur y Horbath (2002: 483), con la ENCUP 2001. Se ha ganado en precisión y se han reducido una serie de preguntas que hacía difusa la identificación de las formas de participación ciudadana.

De acuerdo con las prácticas de participación ciudadana, en las 11 acciones de participación ciudadana no políticas, los jóvenes muestran en la mayoría una menor participación con respecto a los no jóvenes o considerados para el estudio como mayores. Mientras que, cuando la comunidad percibe problemas sociales y están interesados en ayudar a resolverlos, se identifican 14 estrategias para tratar de organizarse socialmente para su resolución, las personas mayores tienen una mayor participación en estas estrategias, observando que al menos un 55.5\% ha tratado alguna forma de organización para resolver problemas comunes, con respecto a los jóvenes que trataron al menos una forma en un $45.6 \%$. Según las formas de organización, con respecto a formar o haber formado parte de diversas organizaciones en algún momento de su vida, encontramos que hay nuevamente una participación menor de los jóvenes frente a los mayores. Por último, el $64 \%$ de los jóvenes manifestaron haber acudido a votar desde el 2000 en al menos una de las 6 elecciones indagadas; principalmente se observó el interés de un 59\%de los jóvenes por acudir a las elecciones presidenciales y en las de presidentes municipales del 53.9\%, aunque en general hubo una participación similar. Por las que menos interés presentaron fue en la elección de los diputados locales, con un $47.3 \%$ y en los Gobernadores de Estado del $47.6 \%$. 
Las pirámides de población con datos expandidos mostraron claramente que la población en México tiene una alta capacidad de participación en acciones de ciudadanía, lo cual es un fenómeno generalizado tanto por sexo como por edades, pero menor entre las mujeres. Los jóvenes muestran tener menor participación en acciones de ciudadanía, y en este grupo de la población, persisten las diferencias de participación entre hombres y mujeres. De la participación electoral, en la pirámide de población se aprecia una generalizada contracción, siendo mucho más fuerte entre las mujeres y especialmente entre los jóvenes.

El primer modelo de participación en acciones de ciudadanía muestra como variables asociadas a las acciones sociales de participación ciudadana algunas características de las personas, como son su grado de escolaridad y el sexo y características regionales como la región donde residen. La escolaridad se ve relacionada con las acciones de participación ciudadana en la medida en que aumentan el grado de escolaridad. La probabilidad es mayor entre las mujeres en casi el doble con respecto a los hombres. Mientras que si los jóvenes pertenecen a la región noroeste, la probabilidad de participación es 9.7 veces mayor con respecto a los jóvenes del noreste.

En el modelo de participación electoral, se pudo establecer que la probabilidad se eleva con la edad, mientras que, aunque con poca fuerza estadística, existe una relación entre la participación electoral y el grado de escolaridad. Por último, la participación electoral de los jóvenes también se ve asociada con la capacidad de los jóvenes de resolver problemas por lo que estas prácticas pueden predecir comportamientos relacionados con la participación electoral.

El cambio generacional en el sistema democrático en México está obligando a que se den procesos de mayor incorporación de los jóvenes a la vida democrática del país, fortaleciendo la transparencia en las instituciones democráticas para incentivar la credibilidad de la población joven que generacionalmente tiene mayor escolaridad y su capacidad de crítica a las propuestas electorales es cada vez mayor.

\section{REFERENCIAS}

- $\quad$ Baczko, B. (1991).Los imaginarios sociales. Memorias y esperanzas colectivas. Buenos Aires: Nueva Visión.

- $\quad$ Bolos, S. (1995).Actores sociales y demandas urbanas. México D. F.: Plaza y Valdés Cultura ciudadana, gobiernos locales y partidos políticos.

- Calhoun, C. (2002). Imagining Solidarity: Cosmopolitanism, Constitutional Patriotism and the Public Sphere. Public Culture, 14 (1).

- $\quad$ Carrión, F. y Dorte W.(compiladores.) (1999). La ciudad, escenario de comunicación. Quito: Facultad Latinoamericana de Ciencias Sociales. 
- Giménez, G. (2000). Materiales para una teoría de las identidades sociales. En J. M. Valenzuela Arce (coord.), Decadencia y auge de las identidades. México: El Colegio de la Frontera Norte-Plaza y Valdés.

- Horbath, J. (2002). Cambio electoral, marginación y formas de manipulación en México: las elecciones de 1994, 1997 y 2000. Revista Convergencia, 9 (27).

- Hosmer, D. W.\& Stanley L. (2000).Applied Logistic Regression, Wiley Series in Probability and Statistics (Second edition). Estados Unidos: John Wiley \& Sons.

- Isin, E. F. (1996). Global City-Regions and Citizenship. En R. Keil, G. R. Wekerle, V. J. Bell y D. V. Bell (eds.), Local Places in the Age of the Global City. Montreal: Institute of Policy Alternatives of Montreal (IPAM)-Black Rose Books.

- Paley, J. (2002). Toward an Anthropology of Democracy.Review of Anthropology, 31.

- $\quad$ Parameshwar, D. (2002). Toward New Imaginaries: an Introduction. Public Culture, 14 (1).

- Portal, M. A. (2004). Ciudadanía y participación: Encrucijada actual para la democracia en México. En N. García Canclini, Reabrir espacios públicos. Políticas culturales y ciudadanía. México: Universidad Autónoma Metropolitana y Plaza y Valdés Editores.

- Secretaría de Gobierno (2003).Encuesta Nacional sobre Cultura Política y Prácticas Ciudadanas 2003 ENCUP-2003. Resumen de Resultados. México: Dirección General de Desarrollo Político.

- Verba, S. (1978).Participation and Political Equality. A Seven Nations Comparison. Chicago: University of Chicago Press.

- Taylor, C. (2002). Modern Social Imaginaries. Public Culture, 14 (1).

- Tejera, H. (2006). Cultura ciudadana, gobiernos locales y partidos políticos en México. Revista Sociológica, 21 (61).

- Winocur, R. \& Horbath, J. (2002). Claves para repensar el problema de la participación ciudadana. En R. Salazar, et al.(coordinadores), Democracias en riesgo en América Latina. México: Ed. Libros en Red. Insumisos Latinoamericanos. Comisión Estatal para el acceso a la información pública del Estado de Sinaloa CEAIPES.

- Zermeño, S. (2004). La democracia impertinente: comités vecinales en una cultura estatal. En N. García Canclini, Reabrir espacios públicos. Políticas culturales y ciudadanía. México: Universidad Autónoma Metropolitana y Plaza y Valdés Editores. 